\title{
Re: "Mortality Attributed to COVID-19 in High-Altitude Populations" by Woolcott and Bergman
}

\author{
Gustavo Zubieta-Calleja, Alfredo Merino-Luna, ${ }^{2}$ Natalia Zubieta-DeUrioste, ${ }^{1}$ \\ N. Freddy Armijo-Subieta, ${ }^{3}$ Jorge Soliz, ${ }^{1,4}$ Christian Arias-Reyes, ${ }^{4}$ Raffo Escalante-Kanashiro, ${ }^{2,5}$ \\ Jose Antonio Carmona-Suazo, ${ }^{6}$ Alberto López-Bascope, ${ }^{7}$ Jose Manuel Calle-Aracena, ${ }^{8}$ \\ Murray Epstein, ${ }^{9}$ and Enrique Maravi ${ }^{10}$
}

Dear Editor,

W E HAVE READ WITH INTEREST the article by Woolcott and Bergman, "Mortality Attributed to COVID-19 in High-Altitude Populations" (Woolcott and Bergman, 2020), and disagree with their conclusion that "Altitude is associated with COVID-19 mortality in men younger than 65 years." It is essential to contrast existing data from Bolivia and Peru to fully weigh the veracity of their conclusions.

Their data overestimate the mortality risk due to underdiagnosis. According to COVID-19 diagnostic policies in the United States, Mexico, and other Latin American countries, tests were only performed in patients with evident symptoms. Such an approach can give rise to inaccurate data in many countries. The Mexican government's data are complex, and there were no travel restrictions between high and lowlands. Furthermore, quoting Woolcott, since "Kong demonstrated a higher proportion of asymptomatic COVID-19 cases in populations located $>3,000 \mathrm{~m}$ than in those located at lower altitudes (*500-2,000 m)" (Woolcott and Bergman, 2020), then the ratio between deaths and confirmed cases increases with increasing altitude, diluting the case fatality rate. The total number of deaths (although inexact) can be used to calculate more precisely the total number of cases (asymptomatic+oligosymptomatic+severe+critical). All these relevant variables change the authors' incidence and mortality rate of COVID-19 completely.

Only considering the analysis of counties and municipalities that reported deaths might be epidemiologically correct. However, it can lead to a case incidence miscalculation at altitude, as there is a risk of death in all regions affected by COVID-19. When analyzing the geographical distribution of illness, providing data on the absence of the studied feature (i.e., deaths per region) is important and must be considered in the final computation of the results and title.

Moreover, their statement "Whether COVID-19 mortality rate is different in populations residing at low and high altitude remains unknown" (Woolcott and Bergman, 2020) is not accurate. Several recent publications and preprints document differences in mortality rates between altitude and lowlands (Rivero and Montoya 2020), peerreviewed in Peru.

In the United States, where there were no travel restrictions, confounding factor of acute ascent of travelers to high altitude with presymptomatic COVID-19 may pose an increased risk compared with highlanders. Tolerance to hypoxia increases with altitude and may be dependent on a higher hemoglobin in COVID-19 patients (Zubieta-Calleja et al., 2020). Table 1 presents data of all permanent residents in Bolivia with strict quarantine and no altitude changes.

The very low initial COVID-19 incidence documented in all high-altitude cities in Bolivia and Peru has been replicated in other parts of the world (data of 23 countries under peer review). Accinelli and Leon Barca (2020) found similar results in Peru. This has been attributed to several environmental and biological factors that may mitigate illness, including (1) high ultraviolet (UV) radiation, (2) dry air, (3) later appearance in high-altitude regions, (4) potential physiological factors such as a hypothesized reduced expression of angiotensin converting enzyme 2 , a membrane enzyme to which the SARS-CoV-2 virus binds and gains entry into the cell, as detailed in a recent review (Danser et al., 2020). The initial slowly increasing slope of cases at high altitude has accelerated over time, nevertheless not to levels documented in lowland areas (Fig. 1). Pun et al. (2020) have

\footnotetext{
${ }^{1}$ High Altitude Pulmonary and Pathology Institute (HAPPI-IPPA), Pulmonary Department, La Paz, Bolivia.

${ }^{2}$ Universidad Peruana de Ciencias Aplicadas (UPC), Lima, Perú.

${ }^{3}$ Universidad Franz Tamayo, La Paz, Bolivia.

${ }^{4}$ Institut Universitaire de Cardiologie et de Pneumologie de Québec, Laval University, Quebec City, Québec, Canada.

${ }^{5}$ Unidad de Cuidados Intensivos Instituto Nacional de Salud del Niño, Lima, Perú.

${ }^{6}$ Hospital Juarez, Mexico City, Mexico.

${ }_{8}^{7}$ Hospital Angeles Mexico, Mexico City, Mexico.

${ }^{8}$ Universidad Autónoma Tomas Frias, Potosí, Bolivia.

${ }^{9}$ University of Miami Miller School of Medicine, Miami, Florida, USA

${ }^{10}$ Prof. Emeritus, Intensive Care, Complejo Hospitalario de Navarra-O, Universidad de Navarra, Pamplona, España.
} 
Table 1. Incidence, Mortality and Case Fatality in Bolivia and Peru during the COVID-19 Pandemic

\begin{tabular}{|c|c|c|c|c|}
\hline Altitudes & $\begin{array}{l}\text { Population } \\
\text { in millions }\end{array}$ & $\begin{array}{c}\text { COVID-19 } \\
\text { incidence in \% }\end{array}$ & $\begin{array}{l}\text { Mortality } \\
\text { in } \%\end{array}$ & $\begin{array}{c}\text { Case fatality } \\
\text { rate in } \%\end{array}$ \\
\hline \multicolumn{5}{|l|}{ Bolivia } \\
\hline Lowlands $<1500 \mathrm{~m}$ & 4.0 & 38.4 & 56.1 & 8.6 \\
\hline Moderate altitude $1500-2500 \mathrm{~m}$ & 3.25 & 26 & 24.2 & 5.5 \\
\hline High altitude $>2500 \mathrm{~m}$ & 4.38 & 35.6 & 19.7 & 3.2 \\
\hline \multicolumn{5}{|l|}{ Peru } \\
\hline Lowlands $<1500 \mathrm{~m}$ & 15.1 & 40.2 & 53.6 & 5.9 \\
\hline Moderate altitude $1500-2500 \mathrm{~m}$ & 4.5 & 23.2 & 28.7 & 3.5 \\
\hline High altitude $>2500 \mathrm{~m}$ & 8.3 & 36.6 & 17.7 & 3.1 \\
\hline
\end{tabular}

highlighted that other environmental features, including seasonal weather patterns and temperature, at different latitudes may be important in viral transmission, which can explain why these results differ from those in Woolcott and Bergman's study of United States and Mexico outcomes.
Zubieta et al. have also stressed the importance of UV radiation in the reduction of COVID-19 at high altitude (http:// altitudeclinic.com/blog/2020/06/covid-19-pubs/).

We hope that the extensive data set presented herein will constitute a platform for enabling future clinical in-

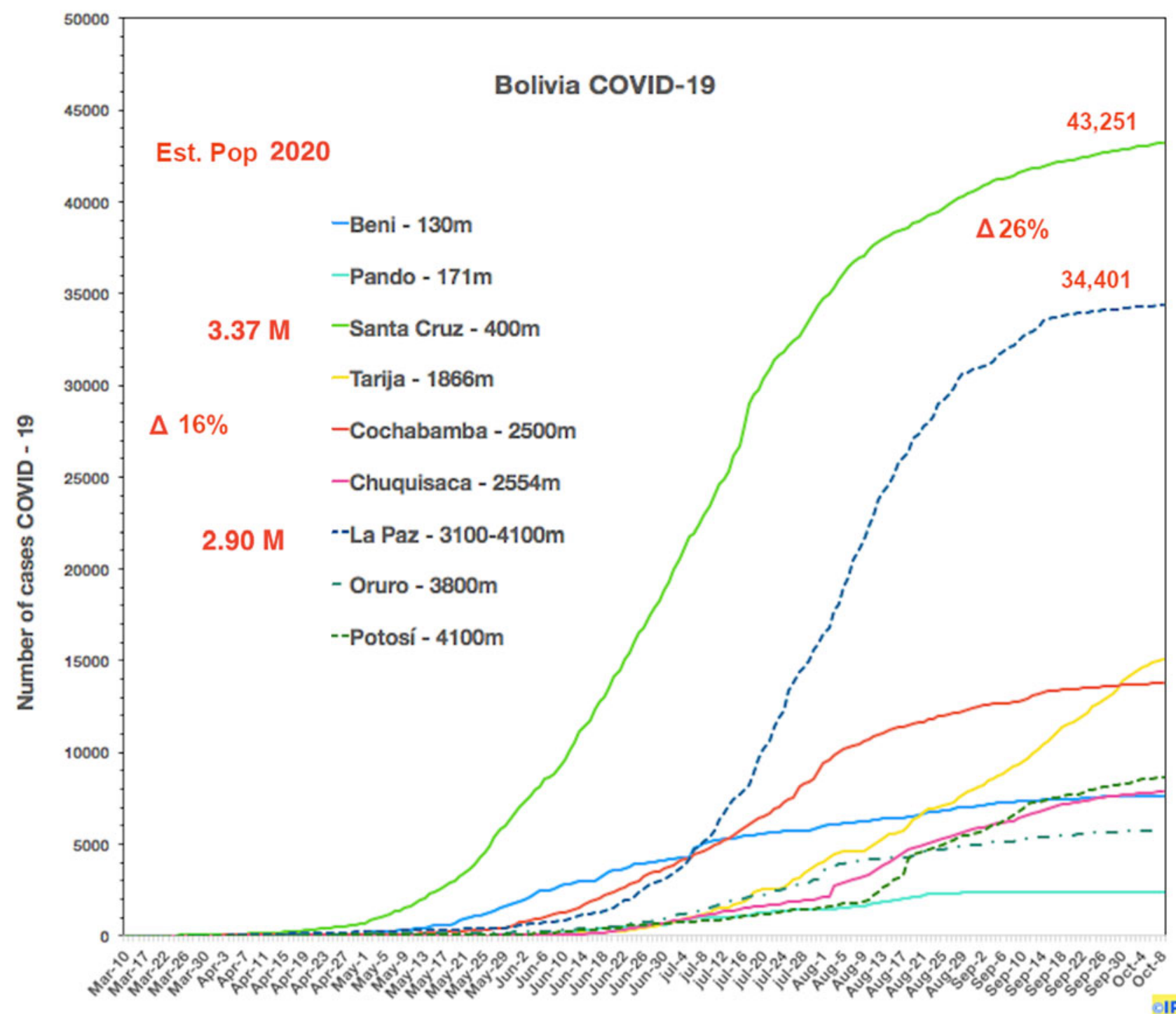

FIG. 1. Bolivia COVID-19 incidence cumulative data, March 10-October 8, 2020. The two main states (departments): La Paz (dashed blue line) and Santa Cruz (top green line), the latter with a 16\% larger population than the first presented $26 \%$ more COVID-19 confirmed cases. Although the pandemic started almost simultaneously in both departments on March 10, there was a COVID-19 "lag" in high-altitude areas, replicated in many high-altitude cities in the world. 
vestigations of this important clinical disorder. According to these data, there is a clear tendency toward lower COVID-19 incidence and lower mortality at high altitude, for all ages in both countries compared with sea level (Table 1).

\section{Authors' Contributions}

G.Z.-C. and N.Z.-D. generated the concept, wrote the article, and provided Figure 1. E.M. suggested writing the letter and approved it. A.M.-L. provided statistics from Peru in the table. N. F.A.S. provided statistics from Bolivia in the table. J.S., C.A.-R., and M.E. gave suggestions, structured, and edited the article. R.E.-K., A.L.-B., and J.M.C.-A. provided information on the subject. J.A.C.-S. provided insight into México. All authors have reviewed and accepted the final article.

\section{References}

Accinelli RA and Leon-Abarca JA. (2020). At high altitude COVID-19 is less frequent: The experience of Peru. Arch Bronconeumol 56:760-761.

Danser AHJ, Epstein M, and Batlle D. (2020). Reninangiotensin system blockers and the COVID-19 pandemic: At present there is no evidence to abandon renin-angiotensin system blockers. Hypertension 75:1382-1385.
Pun M, Turner R, Strapazzon G, Brugger H, and Swenson ER. (2020). Lower incidence of COVID-19 at high altitude: Facts and confounders. High Alt Med Biol 21:217-222.

Rivero AC, and Montoya M. (2020). COVID19 en población residente de zonas geográficas a alturas superiores a 2500 msnm (in Spanish). SITUA 23:19-26.

Woolcott OO, and Bergman RN. (2020). Mortality attributed to COVID-19 in high-altitude populations. High Alt Med Biol 21:409-416.

Zubieta-Calleja GR, Zubieta-DeUrioste N, Venkatesh T, Das K, and Soliz J. (2020). COVID-19 and pneumolysis simulating extreme high-altitude exposure with altered oxygen transport physiology; multiple diseases, and scarce need of ventilators: Andean Condor' s-eye-view. Rev Recent Clin Trials [Epub ahead of print]; DOI: 10.2174/1574887115666200925141108.

Address correspondence to:

Gustavo Zubieta-Calleja, MD

High Altitude Pulmonary and Pathology Institute (HAPPI-IPPA)

Pulmonary Department

Av. Copacabana Prolongación \# 55, La Paz Bolivia

E-mail: gzubietajr@gmail.com

Received October 13, 2020; accepted in final form November 20, 2020. 